\title{
Commentary: Finding a job in cardiothoracic surgery: Is it @ check for updates who you know rather than what you know?
}

\author{
Travis C. Geraci, $\mathrm{MD},{ }^{\mathrm{a}}$ and Thomas $\mathrm{Ng}, \mathrm{MD}^{\mathrm{b}}$
}

\footnotetext{
From the a Department of Cardiothoracic Surgery, New York University—Langone Health, New York, NY; and ${ }^{\mathrm{b}}$ Department of Surgery, Warren Alpert Medical School of Brown University, Providence, RI.

Disclosures: Authors have nothing to disclose with regard to commercial support.

Received for publication March 23, 2019; accepted for publication March 25, 2019; available ahead of print May $14,2019$.

Address for reprints: Thomas Ng, MD, 2 Dudley St, Suite 470, Providence, RI 02905 (E-mail: tng @ usasurg.org). J Thorac Cardiovasc Surg 2019;158:642-3

$0022-5223 / \$ 36.00$

Copyright (c) 2019 by The American Association for Thoracic Surgery

https://doi.org/10.1016/j.jtcvs.2019.03.104
}

In 2003, Salazar and colleagues ${ }^{1}$ surveyed cardiothoracic residents, revealing that $72 \%$ found the process of finding their first job to be difficult, with $20 \%$ receiving no job offers. A subsequent survey by Cooke and colleagues ${ }^{2}$ confirmed these findings, reporting residents without job offers had increased to $38 \%$ by 2008 . The article published in this month's Journal by Sterbling and colleagues ${ }^{3}$ suggests that the process of securing a job after training continues to plague our graduating residents.

In a web-based survey of recent cardiothoracic graduates, Sterbling and colleagues ${ }^{3}$ found that $80 \%$ of residents have signed a contract before completing training, leaving $20 \%$ unemployed. Furthermore, $36 \%$ pursued additional training. It was not stated whether these residents were unable to find a job, felt unprepared, or sought advanced training given their career goals. The highest-ranking factors affecting job selection were mentorship and type of practice (academic vs private practice). More than $60 \%$ of residents reported a lack of support/resources during their job search.

With a limited response rate of only $12.8 \%$, it is difficult to draw firm conclusions from the survey. Equally, there was no separation of residents by training design (such as 2-year, 3-year, or integrated programs) or employment specialty (cardiac, thoracic, or mixed practice). Yearly assessment, perhaps associated with annual meetings, before graduation, or linked with the Thoracic Surgery Directors Association exam as Cooke and colleagues ${ }^{2}$ mandated, would generate more consistent and reliable data.

What exactly makes the job-finding process so difficult? Is there a decline in surgical volume? Are surgeons delaying retirement? Are we training too many residents? Given the 80-hour work restrictions, are employers biased toward more experienced candidates? Multiple factors likely contribute to the issue. Transitioning from a

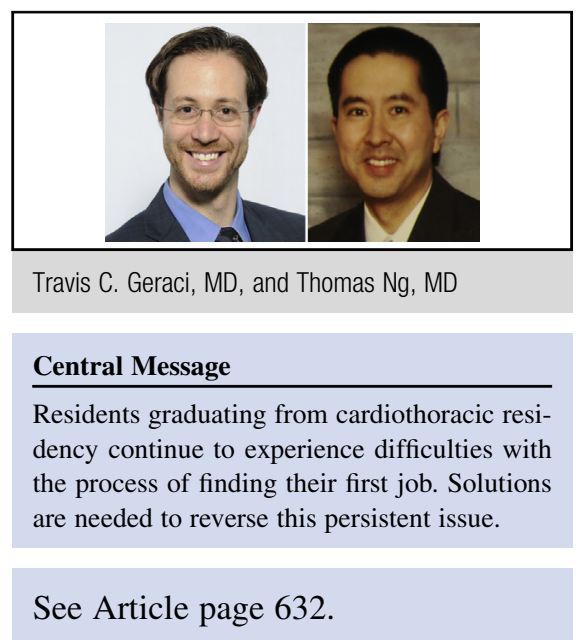

structured educational system, residents must traverse (often for the first time) the more biased and opaque processes of employment. Sterbling and colleagues ${ }^{3}$ report that when seeking a job, $64 \%$ of residents sought assistance from their program director or faculty, $13 \%$ contacted previous mentors, and $50 \%$ had "prior knowledge of openings." As one respondent portrayed in the free-text comments published alongside the survey, the "process [of finding a job] depends on one's network and connections as much or more than operative skill, clinical acumen, and research productivity." ${ }^{3}$ Establishing a more formal, transparent, and centralized space for job listing and communication is a potential target for improvement.

Despite an average starting salary of $\$ 375,588$, a significant number of residents reported needing more support for contract negotiation (70\%) and salary navigation $(77 \%)$, as reported by Sterbling and colleagues. ${ }^{3}$ A hidden gem of data is the reported equality of median starting salaries between women and men. Although the factors influencing compensation are complex, greater transparency should be prioritized. Approximately half of our residents seek legal counsel to ensure a fair contract. ${ }^{3}$ As a community of surgeons, we should promote contracts with clear definitions of productivity, insurance coverage, and benefits, and help our graduates avoid potential legal pitfalls such as noncompete agreements. 
Although a first job may not optimize all aspects of employment—such as location, practice type, mentorship, and compensation - the mechanisms of ensuring quality employment after training can be improved. Changes should be implemented expeditiously not only for the sake of our current residents but also for our future as a specialty, because dissatisfaction and burnout further detract from recruiting high-quality applicants.

\section{References}

1. Salazar JD, Lee R, Wheatley GH III, Doty JR. Are there enough jobs in cardiothoracic surgery? The thoracic surgery residents association job placement survey for finishing residents. Ann Thorac Surg. 2004;78:1523-7.

2. Cooke DT, Kerendi F, Mettler BA, Boffa DJ, Mehall JR, Merrill WH, et al. Update on cardiothoracic surgery resident job opportunities. Ann Thorac Surg. 2010;89: 1853-8.

3. Sterbling HM, Molena D, Rao SR, Stein SL, Litle VR. Initial report on young cardiothoracic surgeons' first job: from searching to securing and the gaps in-between. J Thorac Cardiovasc Surg. 2019;158:632-41.e3. 